\title{
Importance of the variability of hydrographic preconditioning for deep convection in the Gulf of Lion, NW Mediterranean
}

\author{
L. Grignon ${ }^{1}$, D. A. Smeed ${ }^{1}$, H. L. Bryden ${ }^{1}$, and K. Schroeder ${ }^{2}$ \\ ${ }^{1}$ National Oceanography Centre, Southampton, UK \\ ${ }^{2}$ CNR-ISMAR, Sede di La Spezia, Italy
}

Received: 15 October 2009 - Published in Ocean Sci. Discuss.: 18 January 2010

Revised: 24 April 2010 - Accepted: 14 May 2010 - Published: 14 June 2010

\begin{abstract}
We study the variability of hydrographic preconditioning defined as the heat and salt contents in the Ligurian Sea before convection. The stratification is found to reach a maximum in the intermediate layer in December, whose causes and consequences for the interannual variability of convection are investigated. Further study of the interannual variability and correlation tests between the properties of the deep water formed and the winter surface fluxes support the description of convection as a process that transfers the heat and salt contents from the top and intermediate layers to the deep layer. A proxy for the rate of transfer is given by the final convective mixed layer depth, that is shown to depend equally on the surface fluxes and on the preconditioning. In particular, it is found that deep convection in winter 20042005 would have happened even with normal winter conditions, due to low pre-winter stratification.
\end{abstract}

\section{Introduction}

Deep convection occurs in regions of the ocean where a high buoyancy loss from a weakly stratified ocean to the atmosphere leads to very intense mixing and deep water formation. The MEDOC-Group (1970) identified the three phases of convection:

- The preconditioning: the stratification weakens but remains positive. This is thought to be created by a cyclonic circulation (MEDOC-Group, 1970; Legg et al., 1998) sometimes associated to topographic features (Hogg, 1973; Madec et al., 1996; Alverson, 1997). Typically, in the Gulf of Lion, the cyclonic circulation is due to the gyre system, on horizontal scale $\mathrm{O}(50-100 \mathrm{~km})$.

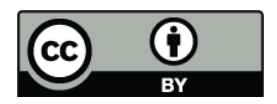

Correspondence to: L. Grignon (laure.grignon@noc.soton.ac.uk)
The seasonal cycle of the surface forcing also plays a role.

- The violent mixing phase: convection is observed in the centre of the convective patch, leading to intense mixing and to a deepening of the mixed layer. Sinking occurs in plumes of horizontal scale $\mathrm{O}(1 \mathrm{~km})$ in which the dense water sinks at vertical speeds up to $10 \mathrm{~cm} / \mathrm{s}$ (Voorhis and Webb, 1970; Schott and Leaman, 1991; Merckelbach et al., 2010). These plumes are mixing agents (Send and Marshall, 1995) associated with a small-scale circulation sometimes modeled as paired, discrete point vortices called hetons (Hogg and Stommel, 1985; Legg and Marshall, 1993). The water mass formed by convection has a composition affected by the frequency of the surface forcing (Artale et al., 2002; Grignon, 2009).

- The sinking and spreading phase: the mixed water sinks and spreads horizontally. The spreading of dense water happens through the action of eddies of horizontal scale $\mathrm{O}(5-10 \mathrm{~km})$, thought to be generated at the edge of the convective patch by the baroclinic instability of the rim current (Gascard, 1978; Testor and Gascard, 2006; Herrmann et al., 2008).

Deep water formation by convection has been observed in the Labrador (Marshall et al., 1998) and Greenland (Schott et al., 1993) Seas and is traditionally thought to be driving the thermohaline circulation (Marshall and Schott, 1999). It has also been observed in the Gulf of Lion, western Mediterranean Sea (MEDOC-Group, 1970) where the Western Mediterranean Deep Water (WMDW) is formed and exported to the Atlantic through the Strait of Gibraltar (Stommel et al., 1973; Bryden and Stommel, 1984; Kinder and Bryden, 1990), hence its potential impact on the oceanic thermohaline circulation.

The composition of the WMDW varies interannually as a result of a combination of processes. Béthoux et al. (1990)

Published by Copernicus Publications on behalf of the European Geosciences Union. 


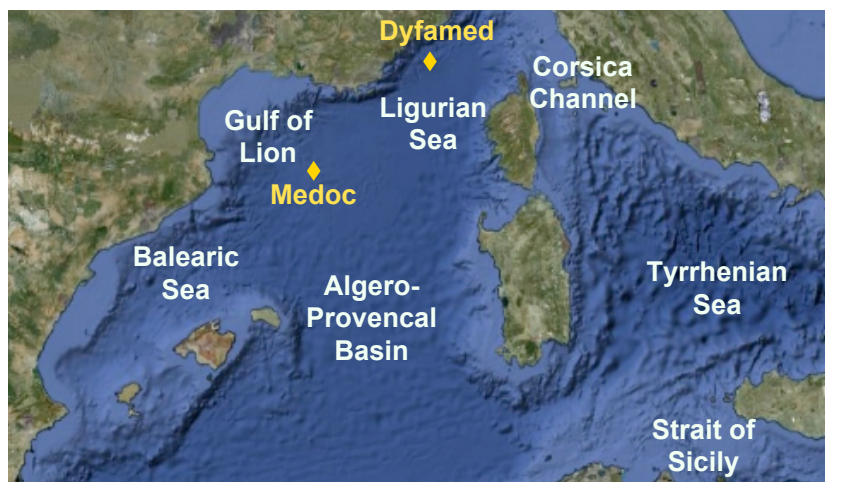

Fig. 1. Satellite view of the Mediterranean Sea. Modified from maps.google.com.

and Krahmann and Schott (1998) found an increasing trend in temperature and salinity of the WMDW since the sixties. Béthoux et al. (1998) concluded that the warming of WMDW was an early effect of climate change. Lopez-Jurado et al. (2005) found that the WMDW, observed in the Balearic Sea, showed a drop in temperature in winter 2004-2005, attributed to particularly strong surface heat loss. Mertens and Schott (1998) studied the interannual variability in mixed layer depth using the sparse available data and a mixed layer model and found high correlation between the final mixed layer depth and the mean surface heat loss over a winter. Variations in deep-water composition are likely to be also linked to a larger-scale evolution of the Western Mediterranean (Rohling and Bryden, 1992; Painter and Tsimplis, 2003). At the western entrance to the Western Mediterranean basin, the inflow of Atlantic water through the Strait of Gibraltar was observed to salinify over the 2003-2007 period (Millot, 2007). At the eastern entrance, a modification of convective regime in the eastern Mediterranean called the Eastern Mediterranean Transient (EMT) led to an export of salt towards the western Mediterranean through the strait of Sicily. Schroeder et al. (2006) emphasised the possible effect of the EMT on deep water formation in the Gulf of Lion, arguing that a progressive heat and salt accumulation in the intermediate layer, due to the EMT propagation, may have led to the formation of a saltier, warmer (and denser) WMDW. The cascading of cold and dense water formed on the Gulf of Lion's shelf, as observed by Font et al. (2007) and Canals et al. (2006) in canyons of the continental slope at the end of winter 2004-2005, is another phenomenon that potentially affects the variability and characteristics of WMDW formation (Béthoux et al., 2002).

In the present paper, we study the variability of hydrographic (rather than dynamic) preconditioning on seasonal and interannual timescales, and assess its impact on deep convection relative to surface forcing. Hydrographic preconditioning is defined as the vertical distributions of salt and heat contents in the water column before convection. We will characterise the variability of deep convection by using proxies such as the maximum winter mixed layer depth and the properties of the WMDW formed.

\section{Seasonal variability of the preconditioning}

\subsection{In the deep convection region}

The MEDAR/MEDATLAS II database is the result of the compilation of different inventories that have been quality checked and interpolated onto a regular spatial grid having a vertical resolution varying from $5 \mathrm{~m}$ near the surface to $500 \mathrm{~m}$ at the bottom (http://modb.oce.ulg.ac.be/backup/ medar/medar.html). We use climatological temperature, salinity and density data at $42^{\circ} \mathrm{N}, 5^{\circ} \mathrm{E}$, traditionally considered to be the centre of convection (Medoc point, Fig. 1).

Figure 2 shows MEDAR climatological temperature and salinity profiles and depth averaged buoyancy frequency for the top (0-100 m), intermediate (100-400 m) and deep (400$2000 \mathrm{~m}$ ) layers. The buoyancy frequency is defined by:

$N^{2}(h)=-\frac{g}{\sigma(h)} \frac{d \sigma}{d h}(h)$

where $\sigma$ is the potential density.

To separate the effects of temperature and salinity on $N^{2}$, we also plot $N_{\text {temp }}^{2}=N^{2}\left(T, S_{0}=36\right)$, that is the buoyancy frequency of a real temperature profile with a constant salinity, and $N_{\text {sal }}^{2}=N^{2}\left(T_{0}=12^{\circ} \mathrm{C}, \mathrm{S}\right)$, the buoyancy frequency of a real salinity profile with a constant temperature. Note that $N_{\text {tot }}^{2} \neq N_{\text {temp }}^{2}+N_{\text {sal }}^{2}$ in general, because of the non linearity of the equation of state, but it is nearly equal for the values chosen for $T_{0}$ and $S_{0}$ (it is valid as long as a linearisation of the equation of state is appropriate around $T_{0}$ and $S_{0}$ ).

The top layer $(0-100 \mathrm{~m})$ exhibits a clear seasonal cycle. It gets warmer and fresher between April and July, building a stratification which is then eroded between July and December. $N_{\text {tot }}^{2}$ reaches very low values between January and March, because of wintertime evaporation that cools the water. Convective vertical mixing subsequently occurs, injecting salt from the intermediate layer into the top layer. The buoyancy frequency shows a peak in July, which is mainly a temperature effect caused by the seasonal increase of the surface radiative fluxes. In the top layer, $N_{\text {tot }}^{2} \sim 10^{-4} \mathrm{~s}^{-2}$.

In the intermediate layer $(100-400 \mathrm{~m})$, taken as representative of the LIW, $N_{\text {tot }}^{2} \sim 10^{-6} \mathrm{~s}^{-2}$, and the salinity stratifying signal predominates while the temperature has a destabilising effect for most of the year (except in May and June). The stabilising or destabilising property of the intermediate layer as a whole are linked to its position relative to the $T$ and $S$ local maxima due to the LIW. Above the $T$ maxima, $N_{\text {temp }}^{2}$ is negative while it is positive below. For $S$, it is the opposite. Note that the two maxima are not exactly at the same depth. The depth range of the intermediate layer is chosen to 

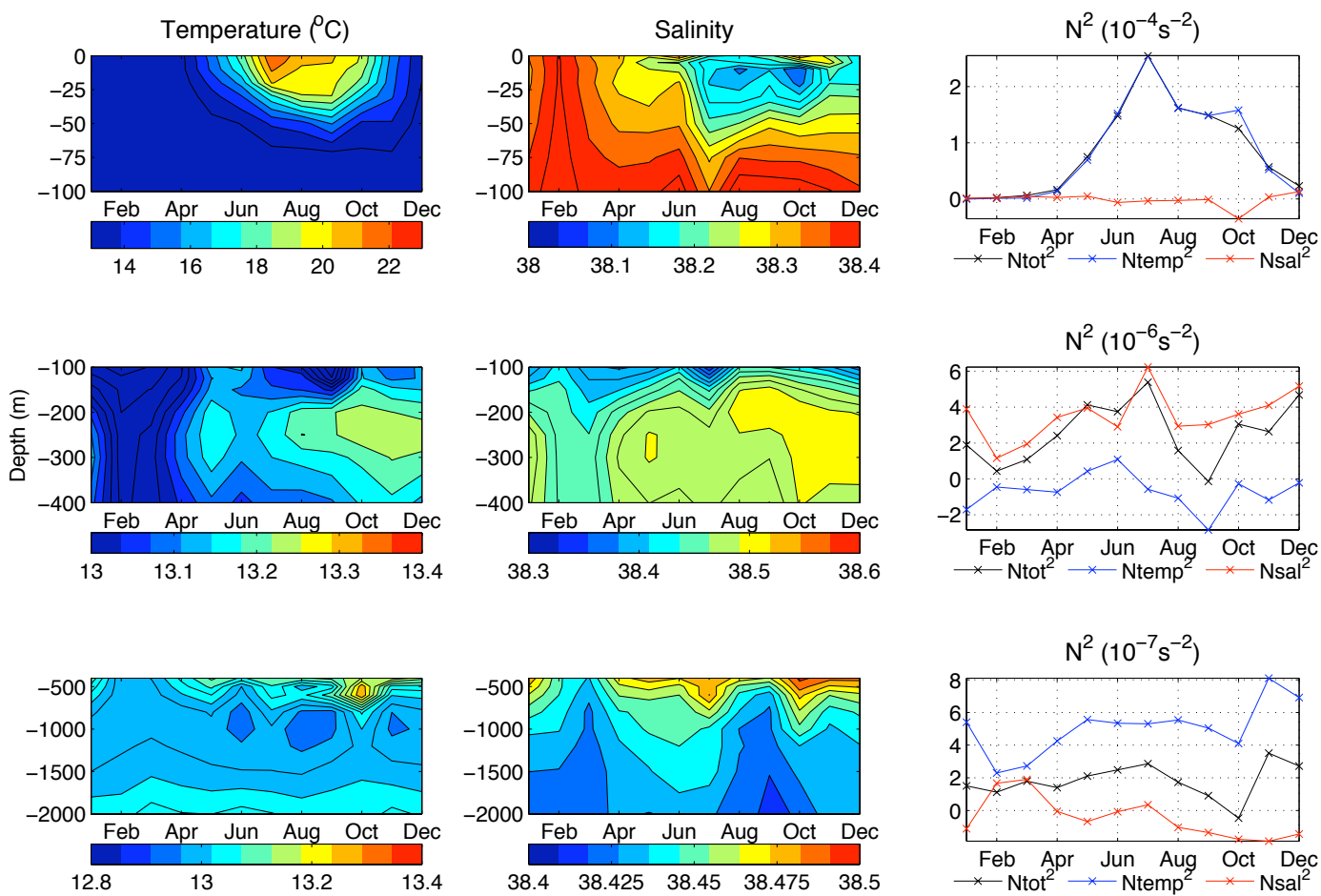

Fig. 2. Temperature (left), salinity (centre) and mean vertical buoyancy gradient (right - see text for definition of $N_{\text {tot }}^{2}, N_{\text {temp }}^{2}$ and $N_{\text {sal }}^{2}$ ) for the top $(0-100 \mathrm{~m})$, intermediate $(100-400 \mathrm{~m})$ and deep (below $400 \mathrm{~m}$ ) layers, over time (months) on the horizontal and depth (m) on the vertical, for the Medar data in the convective area.

illustrate the stratification associated with the LIW. Thus the bottom of the layer is set to be close to the salinity and temperature maxima and does not include the deeper part of the LIW. The temperature and salinity profiles show the erosion of the stratification in February and March, due to convection. The layer then gets saltier and warmer for the rest of the year, and reaches a maximum temperature and salinity in December. The buoyancy frequency shows two maxima, one in July, associated with summer stratification, and another in December. The causes and consequences of the December maximum on convection will be investigated separately.

In the deep layer (below $400 \mathrm{~m}$ ), the temperature has a stabilising effect while the salinity is destabilising. The non linearity of the equation of state under these pressure conditions is such that $N_{\text {tot }}^{2} \neq N_{\text {temp }}^{2}+N_{\text {sal }}^{2}$. Temperature and salinity are much more homogeneous in depth and less variable in the deep layer than above. The annual cycle of temperature shows a warming in October, around $1000 \mathrm{~m}$ depth, which appears to be caused by the lower position of the LIW layer in the water column. The salinity shows two minima. The first one occurs in March and is attributed to convection: convective mixing redistributes salt vertically, resulting in a salinity decrease for the saltiest layers. The second minimum occurs in September. As it is not accompanied by a similar signal above $200 \mathrm{~m}$, it is attributed to lateral advection.
Salinity and temperature fluctuations have little impact on the buoyancy frequency which remains weak $\left(N_{\text {tot }}^{2} \sim 10^{-7} \mathrm{~s}^{-2}\right)$ below $400 \mathrm{~m}$.

\subsection{In the Ligurian Sea}

\subsubsection{From Dyfamed data}

Since 1991, the Laboratoire d'Océanographie de Villefranche has conducted almost monthly cruises in the Ligurian Sea in the framework of the Dyfamed investigation (Marty et al., 2002; Marty and Chiaverini, 2010). The data are available at $43.25^{\circ} \mathrm{N}, 7.52^{\circ} \mathrm{E}$ (Fig. 1) with a vertical resolution of $2 \mathrm{db}$ (http://www.obs-vlfr.fr/sodyf/), but we use a $10 \mathrm{db}$ average in the present analysis. This site is considered representative of hydrographic preconditioning as is it located along the Ligurian Current which flows towards the Medoc area.

To study the seasonal cycle, an average Dyfamed year is calculated for temperature, salinity and buoyancy frequency by first interpolating the profiles to obtain daily values between 1995 and 2004, and then calculating an average profile for each month (Fig. 3). This approach was taken to give equal weighing to all years regardless of the sampling day. The color scale is the same as Fig. 2, to allow comparison.

In the top $(0-100 \mathrm{~m})$ layer, there is a similar, although shallower, post-winter (March to August) restratification as 

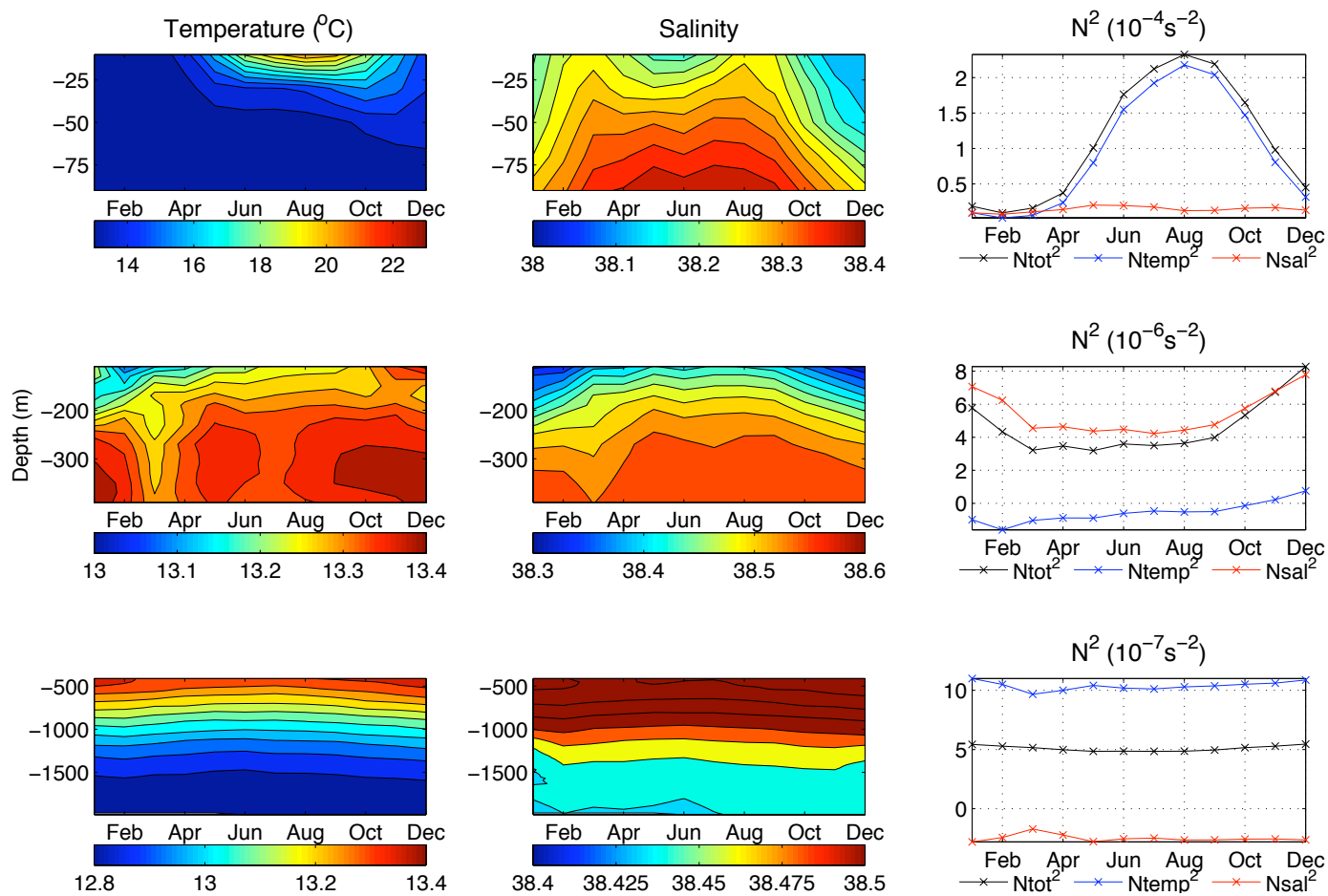

Fig. 3. Temperature (left), salinity (centre) and mean vertical buoyancy gradient (right - see text for definition of $N_{\text {tot }}^{2}, N_{\text {temp }}^{2}$ and $N_{\text {sal }}^{2}$ ) for the top $(0-100 \mathrm{~m})$, intermediate $(100-400 \mathrm{~m})$ and deep (below $400 \mathrm{~m}$ ) layers, over time (months) on the horizontal and depth (m) on the vertical, for the Dyfamed data.

observed in the Medoc area. Winter temperatures are lower, and the salinity varies less, at Medoc than at Dyfamed, which is consistent with convection being more intense in the Medoc region than in the Ligurian Sea.

The intermediate $(100-400 \mathrm{~m})$ layer shows signs of convection, particularly in the temperature data. The LIW seems to lie slightly deeper in the water column at the Dyfamed site, which could be attributed to the cyclonic circulation around the convective area that causes a doming of the isopycnals at the centre of the gyre, less intense in summer, but still present. The stratification also shows signs of erosion by convection, particularly in March. However, the buoyancy frequency reaches a maximum in December, as previously observed at Medoc.

In the deeper layers, the stratification is stronger at Dyfamed than in the Medoc area, which is more affected by convection. The deep layer is denser at the Dyfamed point, but none of these profiles are full depth ones, so the deep layer is not necessarily representative of bottom water.

\subsubsection{Comparison with Medar data}

Medar and Dyfamed data sets were also compared at the Dyfamed site. They show very good qualitative agreement in the seasonal cycle and the December maximum of stratification is found in both data sets. In the Medar data, the December maximum is higher at Dyfamed $\left(8 \times 10^{-6} \mathrm{~s}^{-2}\right)$ than at Medoc $\left(5 \times 10^{-6} \mathrm{~s}^{-2}\right)$, where convection is known to be more intense. Discrepancies are found at Dyfamed between Medar and Dyfamed $\left(10 \times 10^{-6} \mathrm{~s}^{-2}\right)$. Because Dyfamed is considered a more consistent data set, we conclude that Medar may underestimate the maximum in the stratification at Medoc.

\section{Interannual variability of the preconditioning at the Dyfamed site}

\subsection{Temperature}

We now study the evolution of the temperature from the Dyfamed data set for the three layers, and for the whole water column (Fig. 4). The values of the mean temperature interpolated at the 1 December for each year between 1995 and 2004 are joined with thick lines and considered representative of the interannual variability of the pre-convection state. Table 1 contains the values of the means, standard deviations (std) and trends for all thick lines. In the following, a trend will be deemed significant if trend $\times 10 \gg$ std.

The seasonal cycle is clearly visible in the top and intermediate layers, where winter temperature drops are signs of convection, for example at the beginning of years 1997, 1999, 2000, 2003 and 2004. The seasonal signal is much 

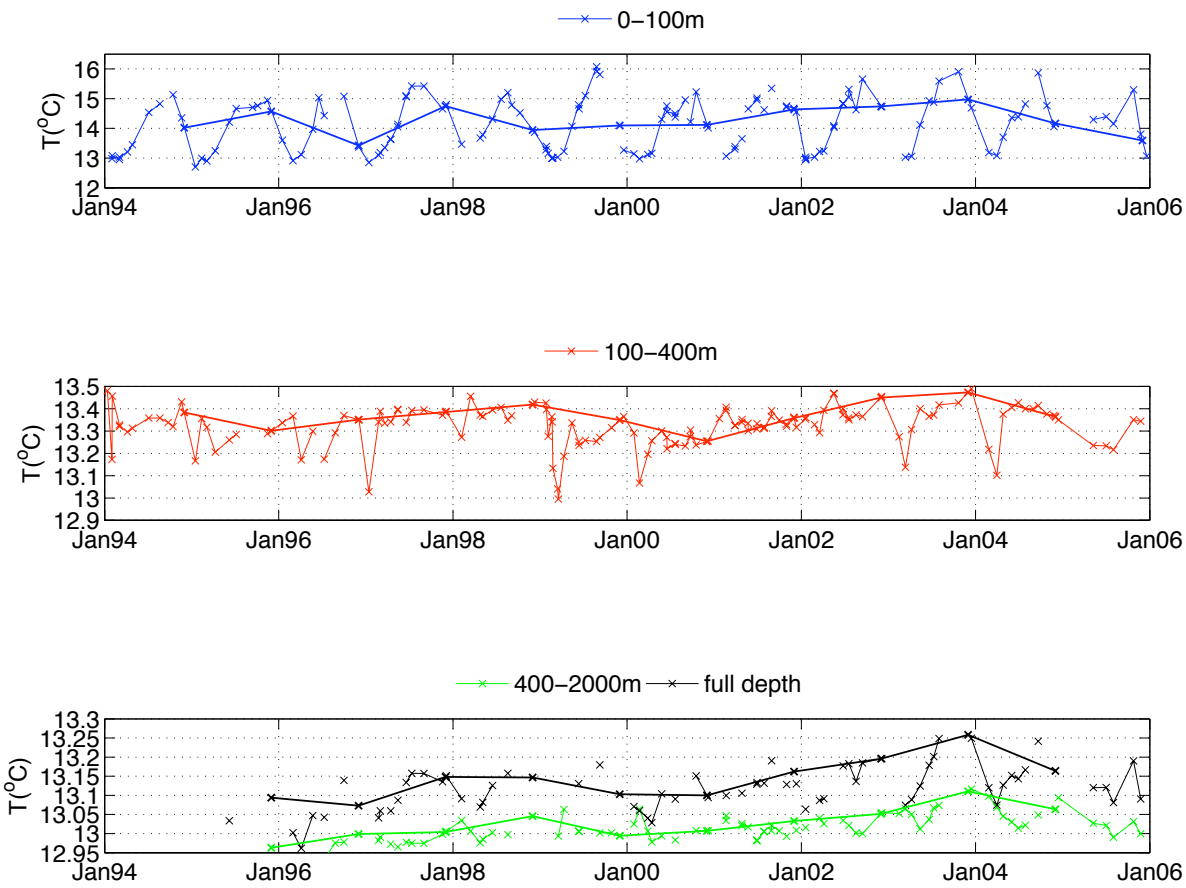

Fig. 4. Temperature $\left({ }^{\circ} \mathrm{C}\right.$ ) from Dyfamed for the 0-100 $\mathrm{m}$ (top), the $100-400 \mathrm{~m}$ (middle), the 400-2000 $\mathrm{m}$ (bottom, green) and the 0-2000 $\mathrm{m}$ (bottom, black) layers. For each plot, the corresponding thick line joins the interpolated values for the 1 December of each year between 1995 and 2004.

Table 1. Mean $(\mathrm{m})$, standard deviation $\left({ }_{\mathrm{std}}\right)$ and trend $(\mathrm{t})$ for the thick plots of Figs. 4 to 6, which represent the depth averaged temperature for each layer on the 1 December of each year between 1995 and 2004.

\begin{tabular}{lcccc}
\hline & $0-100 \mathrm{~m}$ & $100-400 \mathrm{~m}$ & $400-2000 \mathrm{~m}$ & $0-2000 \mathrm{~m}$ \\
\hline$T_{\mathrm{m}}\left[{ }^{\circ} \mathrm{C}\right]$ & 14.34 & 13.37 & 13.03 & 13.14 \\
$T_{\text {std }}\left[{ }^{\circ} \mathrm{C}\right]$ & 0.47 & 0.07 & 0.04 & 0.06 \\
$T_{\mathrm{t}}\left[{ }^{\circ} \mathrm{C} / \mathrm{y}\right]$ & 0.056 & 0.009 & 0.012 & 0.013 \\
$S_{\mathrm{m}}[\mathrm{psu}]$ & 38.176 & 38.485 & 38.494 & 38.477 \\
$S_{\text {std }}[\mathrm{psu}]$ & 0.076 & 0.027 & 0.015 & 0.014 \\
$S_{\mathrm{t}}[\mathrm{psu} / \mathrm{y}]$ & 0.0037 & 0.0030 & 0.0043 & 0.0041 \\
$\rho_{\mathrm{m}}\left[\mathrm{kg} / \mathrm{m}^{3}\right]$ & 28.56 & 29.02 & 29.10 & 29.06 \\
$\rho_{\mathrm{std}}\left[\mathrm{kg} / \mathrm{m}^{3}\right]$ & 0.148 & 0.030 & 0.004 & 0.011 \\
$\rho_{\mathrm{t}}\left[\mathrm{kg} / \mathrm{m}^{3} / \mathrm{y}\right]$ & -0.0094 & 0.0005 & 0.0009 & 0.0003 \\
\hline
\end{tabular}

weaker in the bottom layer, where observations are also less dense.

Table 1 shows a non-significant warming in the top and intermediate layers. For the bottom layer, however, the warming of $0.012^{\circ} \mathrm{C} /$ year is significant and results in a warming trend for the mean temperature of the whole column above $2000 \mathrm{~m}$ of $0.013{ }^{\circ} \mathrm{C} /$ year, comparable to the trend of $0.011^{\circ} \mathrm{C} /$ year obtained by Lopez-Jurado et al. (2005) below $600 \mathrm{~m}$ in the Balearic Sea. We also find that this trend is not followed in the deep layer in December 2004, as they observed in the deep water of the Balearic Sea in summer 2005. Marty and Chiaverini (2010) found, at the Dyfamed site, a trend of $0.005^{\circ} \mathrm{C} / \mathrm{year}$ at $2000 \mathrm{~m}$ depth which is of the same order of magnitude.

\subsection{Salinity}

Figure 5 presents the evolution of the salinity of Dyfamed, under the same format as for the temperature. Table 1 contains the values of the means, standard deviations and trends for all thick lines of Fig. 5.

As for the temperature data, the seasonal cycle for salinity can be observed in the top and intermediate layers, although the interannual variability has a larger amplitude compared to that of the seasonal cycle. The salinity of the top and intermediate layers drops in December-January for most years, as a result of advection, and then increase quickly due to convection (February-March).

The salinity in the top layer shows an important interannual variability compared to the seasonal one, and no significant trend. The variability in the intermediate layer is less than in the top layer (smaller std).

The deep layer is getting saltier at a significant rate of $0.0043 \mathrm{psu} / \mathrm{year}$, close to the trend of $0.003 \mathrm{psu} / \mathrm{year}$ observed by Lopez-Jurado et al. (2005) and to the trend of $0.0022 \mathrm{psu} / \mathrm{year}$ observed at Dyfamed at $2000 \mathrm{~m}$ by Marty and Chiaverini (2010). They also found a small decrease of 

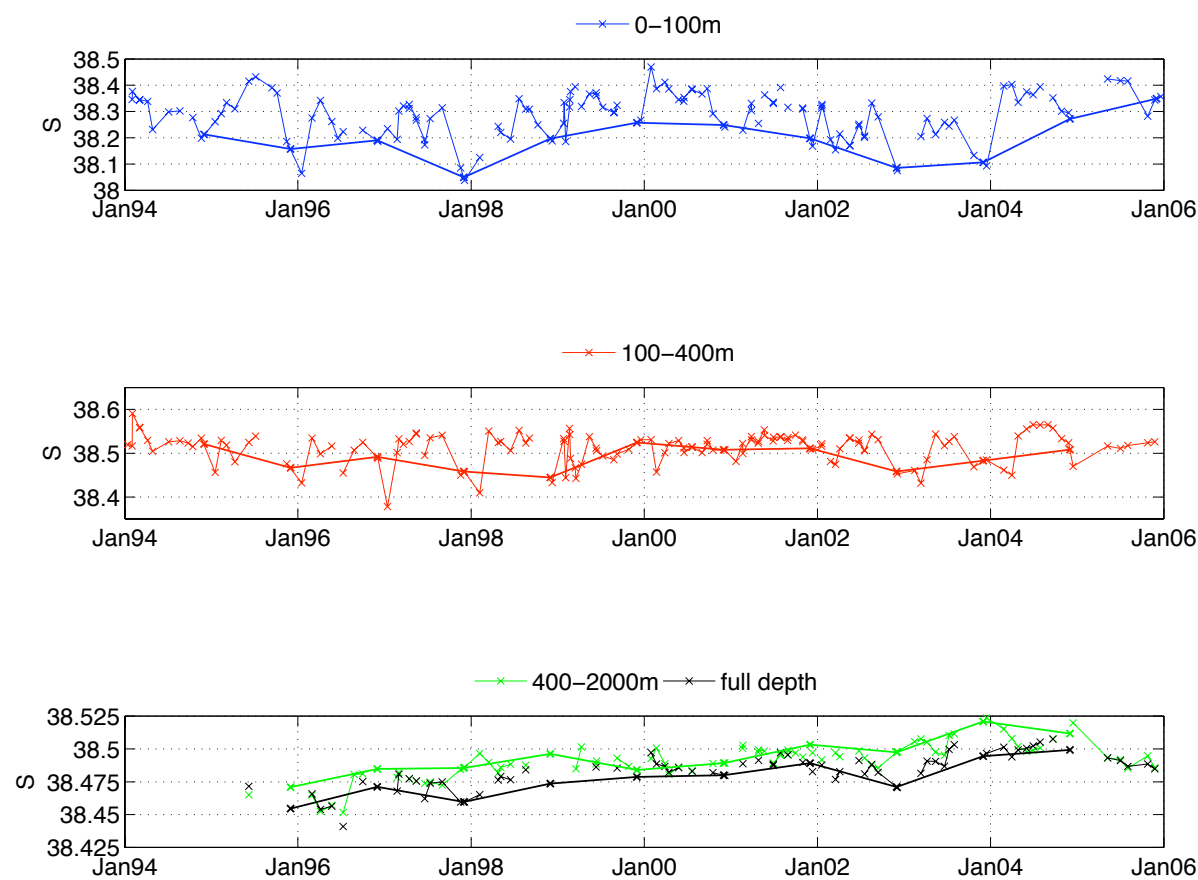

Fig. 5. Salinity from Dyfamed for the 0-100 m (top), the 100-400 m (middle), the 400-2000 m (bottom, green) and the 0-2000 $\mathrm{m}$ (bottom, black) layers. For each plot, the corresponding thick line joins the interpolated values for the 1 December of each year between 1995 and 2004.

the salinity in summer 2005 that we do not observe at the Dyfamed site and that could be due to cascading. The deep trend results in a significant salinification trend of $0.0041 \mathrm{psu} / \mathrm{year}$ in average for the whole water column between the surface and $2000 \mathrm{~m}$.

\subsection{Density}

Figure 6 shows the evolution of the potential density from Dyfamed, following the same format as previously. Table 1 contains the values of the means, standard deviations and trends for all thick lines.

The potential density of the top layer exhibits a seasonal cycle with maxima in density occurring in January/February, when surface heat loss is strongest, and minima in late summer/early fall, due to surface heating. In the intermediate layer, for most years, the density minimum occurs in December or January. This is consistent with the December maximum in the stratification observed in the Dyfamed and Medar records. Indeed, if we consider a constant density at a given depth, an increase in density above will lead to a smaller gradient, hence a weaker stratification; a lower density above will lead to a stronger stratification.

The potential density in the top and intermediate layers does not show significant trends over the 1995-2004 period. However, the deep layer appears to be getting denser at a significant but slow rate of $9 \times 10^{-4}\left(\mathrm{~kg} / \mathrm{m}^{3}\right) /$ year. The deep layer is getting warmer and saltier, and yet denser hence the effect of the salinity on the density predominates. The trends observed in the deep layer for temperature, salinity and density are similar to that observed by Lopez-Jurado et al. (2005) in the Balearic Sea, hence we conclude that they are due to basin scale changes. The trend observed in density of the deep layer does not result in a significant trend for the whole column, whose variability is dominated by that of the top and intermediate layers.

Figure 6 shows that the potential density at the beginning of December increased by about $0.4 \mathrm{~kg} / \mathrm{m}^{3}$ in the top layer over the period 2004-2006, and by about $0.05 \mathrm{~kg} / \mathrm{m}^{3}$ in the intermediate layer over the period 2003-2006. Lopez-Jurado et al. (2005) observed an increase of the density of the water below $600 \mathrm{~m}$ in the Balearic Sea between fall 2004 and summer 2005 of $0.03 \mathrm{~kg} / \mathrm{m}^{3}$. A possible scenario would be that the intense convection of winter 2004-2005 in the Gulf of Lion transferred the increased density to the deep water, while it did not during the previous mild winters. Hence the increase of the density of the deep water would be due to that of the top and intermediate waters before convection rather than to the high buoyancy fluxes that only increased the rate of transfer of properties to the deep water. The increase of potential density observed in the top and intermediate layers for winters 2004-2005 is due to both an increase of the salinity and a decrease of the temperature. 

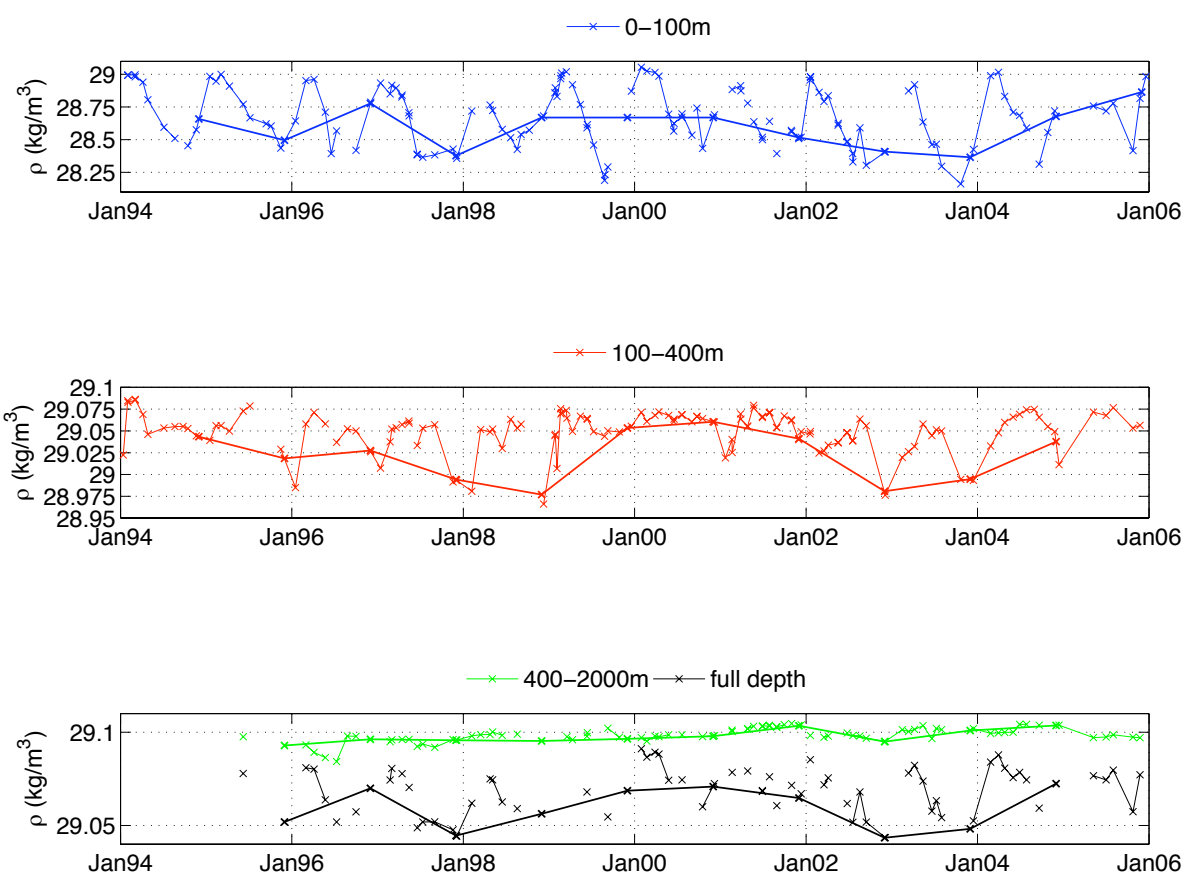

Fig. 6. Potential density from Dyfamed for the 0-100 m (top), the 100-400 m (middle), the 400-2000 m (bottom, green) and the 0-2000 m (bottom, black) layers. For each plot, the corresponding thick line joins the interpolated values for the 1 December of each year between 1995 and 2004.

\subsection{Stratification}

For each layer, Fig. 7 shows the vertical buoyancy gradients $N_{\text {tot }}^{2}, N_{\text {temp }}^{2}$ and $N_{\text {sal }}^{2}$ for all Dyfamed profiles between 1994 and 2006. The summer maxima of stratification for the top layer and the winter maxima for the intermediate layer are joined by thick pink lines.

The maximum of $N_{\text {tot }}^{2}$ varies from year to year, as does the date at which it is reached (although we are limited in our analysis by the frequency at which the profiles have been obtained). $N_{\text {tot }}^{2}$ reaches its annual maximum in late summer in the top layer, and in winter in the intermediate layer. While the surface annual maximum in stratification is due to surface radiative heating, the intermediate winter maximum is likely to be of advective origin.

The interannual variability of the winter maximum of the intermediate layer presents striking similarities with the potential density between 2000 and 2005. The stratification in the intermediate layer increases over the 2000-2003 period, while the potential density decreases. Between December 2002 and December 2004, the density increase coincides with a decrease of the stratification. As the density of the intermediate layer increases, it gets closer to the density of the water just below, hence decreasing the vertical gradient and leading to a water column that can be eroded more easily.

Convection in winter 2004-2005 was very intense not only because of very high air-sea fluxes but also because the strat- ification was quite weak (Schroeder et al., 2010). Summer heating did not lead to a stratification in the top layer as high as in the previous years, and the winter maximum in the intermediate layer was lower than in the two previous years. In the following section we further examine the relative importance of preconditioning on convection.

\section{Importance of preconditioning in setting the convec- tive mixed layer depth}

\subsection{Buoyancy fluxes}

The buoyancy fluxes are calculated from NCEP (Marshall and Schott, 1999):

$B=\frac{g}{\rho_{0}}\left(\frac{\alpha_{\theta}}{c_{\mathrm{W}}} H+\rho_{0} \beta_{\mathrm{s}} S(E-P)\right)$

where $H$ is the total heat flux in $\mathrm{W} / \mathrm{m}^{2}$, i.e. the sum of the latent, sensible and radiative (long- and short-wave) fluxes, $E$ is the evaporation in $\mathrm{m} / \mathrm{s}, P$ is the precipitation in $\mathrm{m} / \mathrm{s}$; so $E-P$ is the net freshwater flux out of the ocean. The other parameters are constant and defined in Table 2. The values used are typical of the surface Mediterranean Sea. We use precipitation data from NCEP while the evaporation is calculated from the NCEP latent heat flux. 

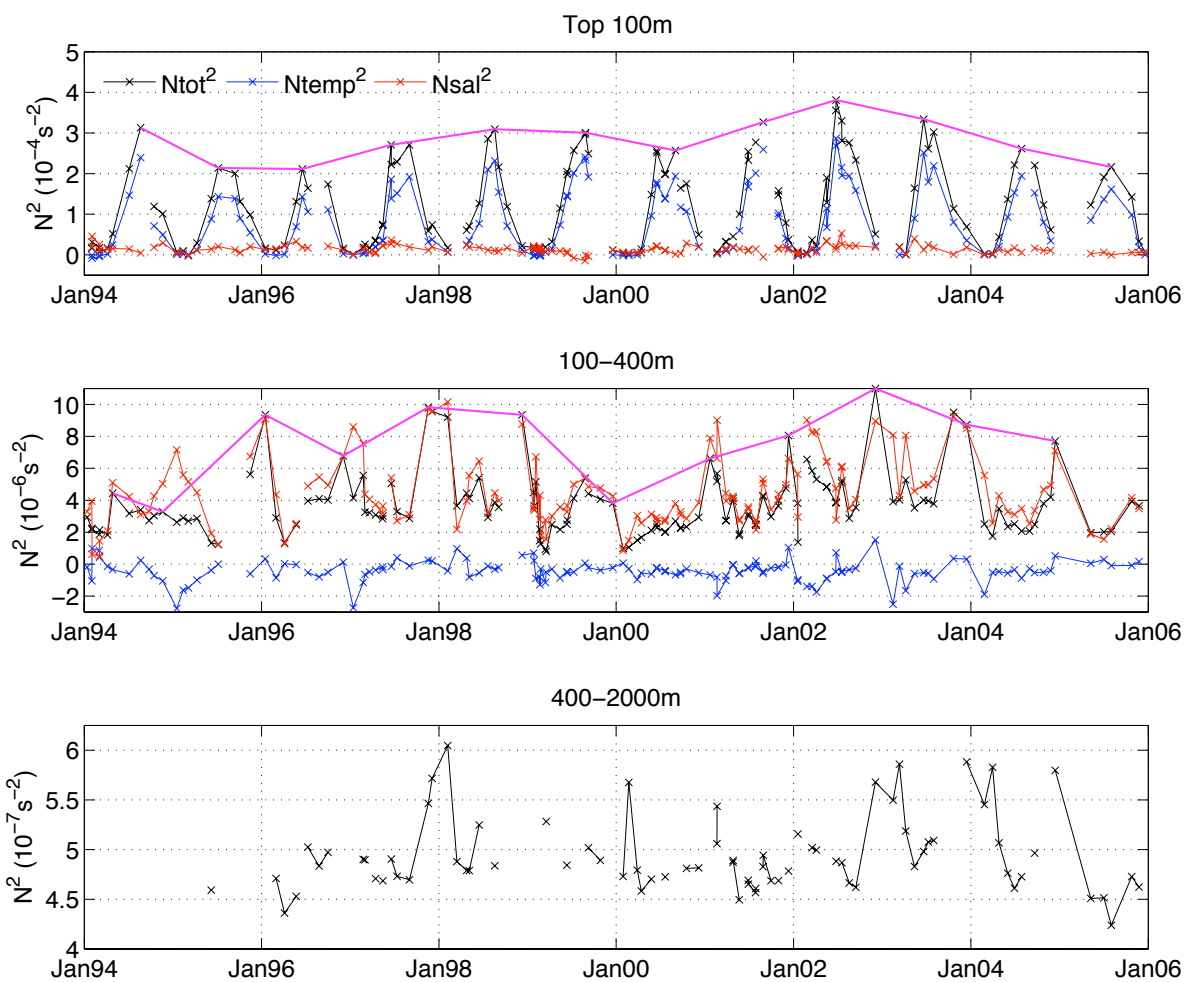

Fig. 7. Depth averaged vertical buoyancy gradients for the top, intermediate and bottom layers from the Dyfamed data set.

Table 2. Definition and value of the parameters used in the surface buoyancy flux calculations.

\begin{tabular}{clc}
\hline Symbol & Definition & Value \\
\hline$g$ & acceleration due to gravity & $9.82 \mathrm{~m} / \mathrm{s}^{2}$ \\
$\rho_{0}$ & constant reference density & $1000 \mathrm{~kg} / \mathrm{m}^{3}$ \\
$\alpha_{\theta}$ & thermal expansion coefficient & $2.0 \times 10^{-4} \mathrm{~K}^{-1}$ \\
$c_{\mathrm{W}}$ & heat capacity of water & $3900 \mathrm{~J} / \mathrm{kg} / \mathrm{K}$ \\
$\beta_{\mathrm{S}}$ & haline contraction coefficient & $7.6 \times 10^{-4} \mathrm{~K}^{-1}$ \\
$S$ & surface salinity (taken constant) & 38.35 \\
\hline
\end{tabular}

We can decompose the buoyancy flux: $B=B_{\mathrm{t}}+B_{\mathrm{s}} . B t$ is the thermal component of the buoyancy flux:

$B_{\mathrm{t}}=\frac{g}{\rho_{0}} \frac{\alpha_{\theta}}{c_{\mathrm{W}}} H$

and $B_{\mathrm{S}}$ its haline component:

$B_{\mathrm{S}}=g \beta_{\mathrm{S}} S(E-P)$

Figure 8 shows the mean buoyancy forcing for the winter period, between the 1 December and the 31 March of the next year, at $\left(3.75^{\circ} \mathrm{E}, 42.86^{\circ} \mathrm{N}\right)$. We consider a constant surface salinity to calculate the haline part of the buoyancy fluxes, which leads to a small error when calculating $B_{\mathrm{s}}$. As $B_{\mathrm{S}} \ll$ $B_{\mathrm{t}}$, this error can be neglected. Periods of strong buoyancy loss coincide both with strong heat loss and net evaporation, because both latent heat and freshwater fluxes are strongly linked to the evaporation.

Figure 8 also shows the average 1960-2004 winter buoyancy fluxes. The dashed blue lines show the mean plus or minus a standard deviation. The mean corresponds to a heat flux of $108.9 \mathrm{~W} / \mathrm{m}^{2}$, and the standard deviation to $32.8 \mathrm{~W} / \mathrm{m}^{2}$. There are no trends in the winter surface buoyancy fluxes, so the warming trend observed in the deep water either results from a change in summer surface buoyancy fluxes, or from a larger scale hydrographic change in the Mediterranean. There were a few intense winters in the 1960s (1962-1963, 1964-1965, 1967-1968 and 1969-1970) during which convection was observed by MEDOC-Group (1970). Winter 1970-1971 was the last one of a series of intense winters after which the winter buoyancy flux does not exceed the mean plus a standard deviation, until winter 2004-2005. In fact, we see that the winter buoyancy flux increases between 2000-2001 and 2004-2005, when it reaches a peak higher than observed in the previous 50 years.

\subsection{Method}

In the following, we neglect the lateral buoyancy fluxes during convection, which limit the deepening of the mixed layer and consider convection as a 1-D process during which $100 \%$ of the surface buoyancy flux is used to deepen the mixed 


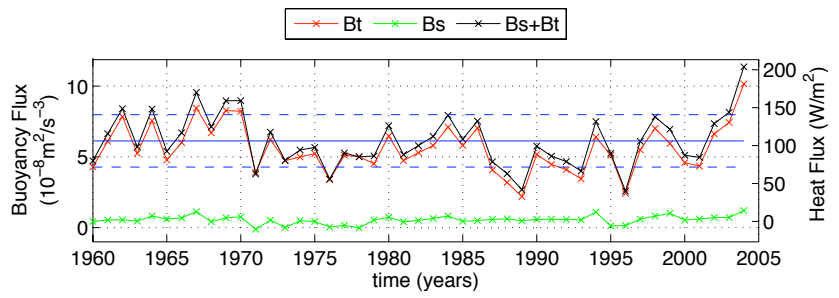

Fig. 8. Mean winter buoyancy fluxes (black) over time (years indicated are the ones in which the winter starts), $B_{\mathrm{t}}$ (red) and $B_{\mathrm{S}}$ (green). The blue line shows the average winter buoyancy fluxes while the dashed blue lines show the mean plus or minus a standard deviation.

layer. The buoyancy flux necessary to reach a depth $h$ can then be defined as the change of buoyancy between a stratified and a partly mixed profile in which the mixed layer has the same density as its base:

$\Delta \mathrm{BC}=\frac{g}{\rho_{0}} \int_{h(t)}^{0}(\rho(h, t)-\rho(z, t=0)) d z$

where $\rho$ the potential density, $\rho_{0}=1000 \mathrm{~kg} / \mathrm{m}^{3}$ (as in the buoyancy fluxes calculation) and $h$ the mixed layer depth. Note that as $\triangle \mathrm{BC}$ refers to a change in buoyancy content, it has the same units as a buoyancy flux integrated over time.

The choice of initial time to define $\rho(z, t=0)$ is critical, hence we initialise the calculation on different density profiles corresponding to the 1 September, October, November and December. An initial profile for December, for example, is obtained by averaging daily interpolated Dyfamed profiles between the 15 November and the 15 December.

We can then compare $\triangle \mathrm{BC}$ with the NCEP surface buoyancy fluxes integrated between the chosen initial date and the end of March, that we will refer to as $\int \mathrm{BF}$, to assess the importance of preconditioning on convection relative to the surface buoyancy fluxes.

\subsection{Importance of preconditioning relative to buoyancy fluxes}

Figure 9 shows $\triangle \mathrm{BC}$ for different values of mixed layer depth $h$ and $\int \mathrm{BF}$ in units of integrated buoyancy flux and equivalent winter integrated heat flux in $10^{2} \mathrm{~W} / \mathrm{m}^{2}$ day (right axis). An integrated heat flux of $-100 \times 10^{2} \mathrm{~W} / \mathrm{m}^{2}$ day corresponds to 100 days at a heat flux of $-100 \mathrm{~W} / \mathrm{m}^{2}$ or 10 days at $-1000 \mathrm{~W} / \mathrm{m}^{2}$.

First note that deep convection requires more buoyancy flux to deepen in December than in fall, which goes against the concept of preconditioning. For example, in 2003, a heat loss of less than $200 \mathrm{~W} / \mathrm{m}^{2}$ day is needed to reach deep convection in September, while a heat loss of $240-250 \mathrm{~W} / \mathrm{m}^{2}$ day is needed in November/December. On the one hand, the fall surface buoyancy loss acts to reduce the stratification in the
Table 3. Mean and standard deviation (std) for the winter integrated buoyancy fluxes (BF) and for the buoyancy flux necessary to reach depths of 100,500 and $2000 \mathrm{~m}$, for a winter starting on the $1 \mathrm{De}$ cember.

\begin{tabular}{lrrrr}
\hline & BF & $100 \mathrm{~m}$ & $500 \mathrm{~m}$ & $2000 \mathrm{~m}$ \\
\hline mean $\left(\mathrm{m}^{2} / \mathrm{s}^{2}\right)$ & -0.637 & -0.294 & -0.696 & -0.817 \\
std $\left(\mathrm{m}^{2} / \mathrm{s}^{2}\right)$ & 0.192 & 0.101 & 0.182 & 0.197 \\
\hline
\end{tabular}

top layer, to an extent that depends on the magnitude of the surface buoyancy loss, hence facilitating convection. On the other hand, advection leads to a maximum in the stratification of the intermediate layer that has a tendency to inhibit convection. The importance of the December stratification maximum is shown by the significant similarities between its interannual variability (Fig. 7) and the December curves for $\triangle \mathrm{BC}$, due to the fact that the calculation performed here is equivalent to running a 1-D model on the chosen Dyfamed profile.

The relative magnitude of $\int \mathrm{BF}$ on Fig. 9 compared to $\triangle \mathrm{BC}$ allows us to estimate the expected final mixed layer depth for one particular winter, in a 1-D framework. For instance, if we consider the bottom plot corresponding to an initialisation at the beginning of December, we expect shallow convection in winters 1995-1996, 1996-1997 and 19971998 to about $200 \mathrm{~m}$, while the next winters were probably more intense, with an expected final mixed layer depth of $1500 \mathrm{~m}$ for winter 1998-1999, and an intense convection reaching deeper than $2000 \mathrm{~m}$ in winters $1999-2000$ and 2000-2001. Convection in the next three winters seems to have been rather weak, with mixed layer depths shallower than $400 \mathrm{~m}$. Even an average ( $<1 \mathrm{std}$ ) winter would lead to $2000 \mathrm{~m}$ winter mixing in 1996, 1999, 2000 and 2004, while a very severe winter ( $>2$ std) would be necessary to cause $2000 \mathrm{~m}$ deep convection in 1997, 2002 and 2003. Thus the depth of winter mixing is strongly dependent on the preconditioning. The massive deep water formation event in 2004-2005 was caused both by the low pre-winter stratification and by the extreme winter buoyancy loss. Even a normal winter would have led to $2000 \mathrm{~m}$ deep convection, so the water column was preconditioned for deep water formation. The severe winter buoyancy loss in 2004-2005 thus led to widespread deep water formation away from the Medoc region (Smith et al., 2008) and resulted in a huge volume of new deep water (Schroeder et al., 2008).

Table 3 shows the 1995-2004 means and standard deviations for the winter integrated buoyancy fluxes and for the buoyancy flux necessary to reach some of the depth levels, considering a winter starting on the 1 December, both in terms of buoyancy and equivalent heat fluxes. The standard deviation (std) is used as a proxy for the variability. The winter integrated surface buoyancy loss has a variability similar to, although slightly smaller than, the variability of the 

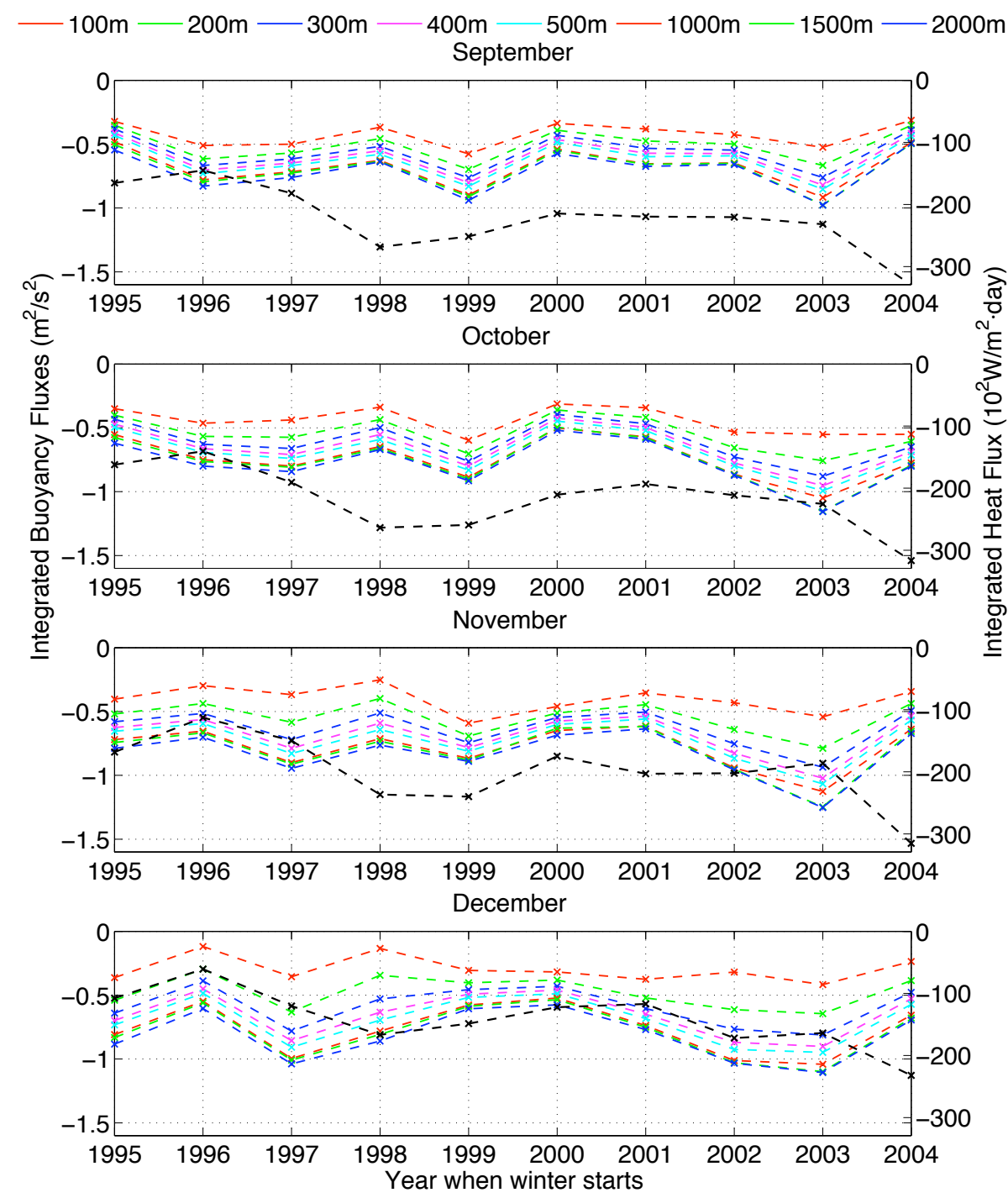

Fig. 9. Buoyancy fluxes that would be necessary to have a convective mixed layer of depth of $h$ and actual integrated buoyancy fluxes (thick black line) for each winter.

amount of buoyancy necessary for the mixed layer depth to reach $2000 \mathrm{~m}$. Hence we can conclude that, under the assumption that the interannual variability at the Dyfamed site is representative of preconditioning at Medoc, the interannual variability of the surface buoyancy loss and that of the preconditioning have an effect of similar magnitude on the final convective depth. As seen previously, most of the buoyancy loss required for convection to reach $2000 \mathrm{~m}$ is actually used to deepen the mixed layer down to $500 \mathrm{~m}$, which is also reflected in the std - most of the interannual variability is due to the intermediate layer. The LIW acts as a strong barrier against convection, hence its variability has an important impact on the convective process.

Table 3 also shows that, even in a 1-D framework in which all the potential energy gained by surface buoyancy loss is used to deepen the mixed layer, an average winter does not lead to a convective mixed layer deeper than $500 \mathrm{~m}$ at the Dyfamed site. If the winter integrated buoyancy flux and the stratification at the start of winter are independent then the probability of convection reaching a given depth may be calculated as follows. We consider the difference between the winter integrated buoyancy flux $X_{\mathrm{BF}}$ and the buoyancy necessary for the mixed layer to reach a depth $h$, which we call $X_{h}$. If $X_{\mathrm{BF}}-X_{h}$ is a random quantity that follows a normal distribution, we can estimate the probability that the mixed layer reaches that depth, i.e. that $X_{\mathrm{BF}}-X_{h}<0$. Table 4 shows the mean, and std of $X_{\mathrm{BF}}-X_{h}$ for $h=500,2000 \mathrm{~m}$ and the probability that convection reaches $h$. We find that only $31 \%$ of winters are expected to lead to deep water formation. 


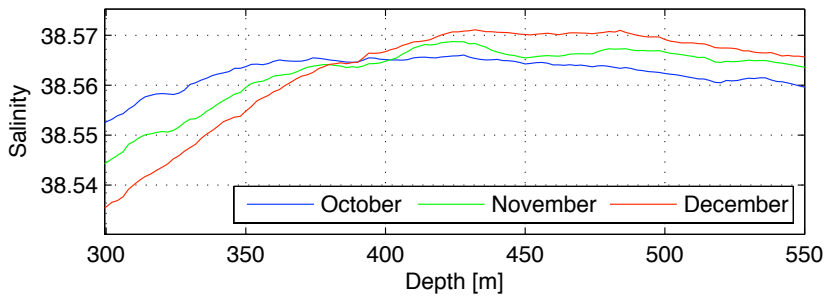

Fig. 10. Climatological Dyfamed salinity profile in the intermediate layer for October, November and December.

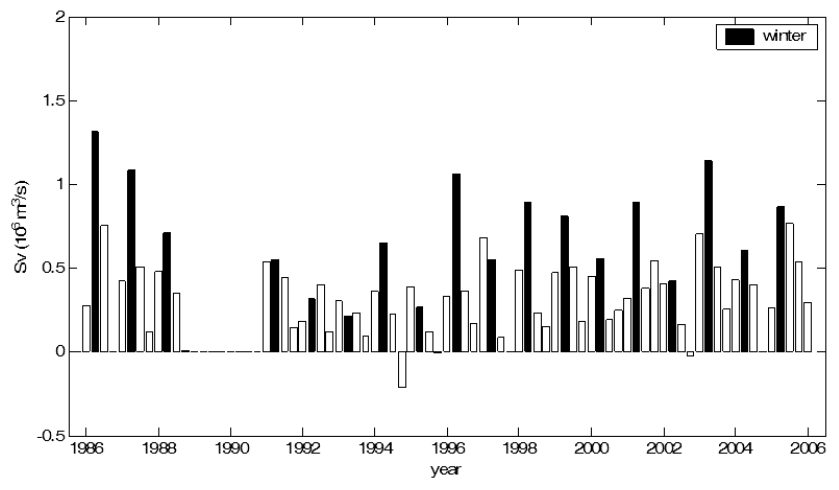

Fig. 11. Evolution of the transport through the Corsica Strait. Each bar corresponds to a transport averaged over 3 months. Black bars indicate the winter transport while the white bars give the spring, summer and fall transports. From Gasparini et al. (2008).

Note that two key assumptions led to this estimate. First, the Dyfamed site was considered representative of preconditioning at Medoc, but dynamic preconditioning (e.g. cyclonic circulation) is expected to make the Medoc site more unstable. Secondly, we consider a 1-D convection process. In the real ocean, lateral buoyancy fluxes due to baroclinic instability limit the mixed layer depth by injecting stratified water into the convective patch.

\section{Causes of the December stratification maximum}

Figure 10 shows salinity profiles around the salinity maximum, which is deeper and of slightly larger amplitude in December than in the two previous months. It is also fresher above $300 \mathrm{~m}$ in December, as indicated by Fig. 3. The combined effect of surface freshening and salinity increase in the intermediate layer leads to a higher salinity gradient and an increased stratification in December. Figure 3 shows that, although the stratification of the intermediate layer is mostly due to the salinity structure, the temperature also contributes to the increase of the stratification through a warming of the LIW layer (Fig. 4).
Table 4. Mean, std of $X_{\mathrm{BF}}-X_{h}$ for $h=500,2000 \mathrm{~m}$, and probability that convection reaches that depth assuming that $X_{\mathrm{BF}}-X_{h}$ follows a normal distribution.

\begin{tabular}{lcc}
\hline$X_{\mathrm{BF}}-X_{h}$ & $h=500 \mathrm{~m}$ & $h=2000 \mathrm{~m}$ \\
\hline mean $\left(\mathrm{m}^{2} / \mathrm{s}^{2}\right)$ & 0.010 & 0.130 \\
std $\left(\mathrm{m}^{2} / \mathrm{s}^{2}\right)$ & 0.242 & 0.266 \\
probability & $48 \%$ & $31 \%$ \\
\hline
\end{tabular}

Astraldi et al. (1990) found, from observations collected during 1986-1987, that the flow through the Corsica Channel increased suddenly in December. Astraldi and Gasparini (1992) explained this increase by the local circulation: the West Corsican Current, that flows on the northwestern side of Corsica, shows little seasonal variability while the Tyrrhenian Current only crosses the Corsica Channel during the cold season. The winter intensification of the transport through the Corsica Channel was confirmed by Vignudelli et al. (1999) and Gasparini et al. (2008), based on longer time series. Figure 11 shows this seasonal transport between winter 1993-1994 and 2004-2005. It presents similarities with the interannual variability observed in the December stratification maximum in the intermediate layer (Fig. 7). Both the transport and the magnitude of the maximum decrease between 1994 and 1995. The low maximum in 2000 corresponds with particularly low transport. However, there are years when the two time series differ, as in 2001, when we do not see a very high maximum while the transport was particularly high. These differences could be due to the variability of the salinity content advected by the Tyrrhenian Current. Moreover, the winter transport shown here is an average over three months, that might hide transport maxima in winter.

Astraldi et al. (1990) also studied the characteristics of the intermediate layer and found that, in winter, it was warmer, saltier and more buoyant east than west of Corsica. The stratification maximum is also found to be associated with an increased salinity and temperature (Figs. 10 and 3), leading to a more buoyant intermediate layer (Fig. 6). This leads us to conclude that the stratification maximum is due to water advected from the Tyrrhenian Sea, that only reaches the Ligurian Sea in December.

\section{Correlation between the buoyancy fluxes and the WMDW composition}

We performed correlation tests between the NCEP surface buoyancy fluxes and the temperature and salinity of the deep water as measured by Béthoux et al. (1998) in the AlgeroProvencal basin between $2000 \mathrm{~m}$ and $2700 \mathrm{~m}$ during 1959 1997 (courtesy of Béthoux), in order to study whether the variability in buoyancy fluxes can affect the composition of the deep water formed. 
Table 5. Correlation tests between NCEP buoyancy fluxes and WMDW $T$ and $S$. The number in brackets is the probability of getting a correlation as large as the observed value by random chance. A very low probability means that the correlation is significant.

\begin{tabular}{rrrrr}
\hline & $\alpha \Delta T$ & $\beta \Delta S$ & $\Delta B_{\mathrm{t}}$ & $\Delta B_{\mathrm{s}}$ \\
\hline$\alpha \Delta T$ & & & & \\
$\beta \Delta S$ & $0.97(0.00)$ & & & \\
$\Delta B_{\mathrm{t}}$ & $0.36(0.02)$ & $0.38(0.01)$ & & \\
$\Delta B_{\mathrm{S}}$ & $-0.03(0.82)$ & $-0.04(0.83)$ & $0.56(0.00)$ & \\
\hline
\end{tabular}

For each year, we decompose the winter averaged (December to March inclusive) buoyancy fluxes $B_{\mathrm{s}}$ and $B_{\mathrm{t}}$ into $B_{\mathrm{s}}($ year $)=\overline{B_{\mathrm{t}}}+\Delta B_{\mathrm{t}}\left(\right.$ year) and $B_{\mathrm{s}}($ year $)=\overline{B_{\mathrm{s}}}+\Delta B_{\mathrm{s}}($ year $)$ where the overbar denotes the average over winters from 1960-1961 to 2003-2004.

The deep water data are interpolated to obtain its temperature and salinity in September of the next year. We can decompose the value for each year as $T$ (year) $=\bar{T}+\Delta T$ (year) and $S$ (year $)=\bar{S}+\Delta S$ (year).

Table 5 contains the correlation coefficients between $\alpha \Delta T, \beta \Delta S, \Delta B_{\mathrm{t}}$ and $\Delta B_{\mathrm{s}}$, where $\alpha$ and $\beta$ are the thermal and haline expansion coefficients in the equation of state. $\alpha \Delta T$ and $\beta \Delta S$ are good approximations to the variation in density due to changes of temperature and salinity. $\Delta B_{\mathrm{t}}$ and $\Delta B_{\mathrm{S}}$ are proportional to changes in surface density due to surface heat and freshwater fluxes. There is an important correlation between the variations in temperature and salinity, due to density compensation. The correlation between $B_{\mathrm{s}}$ and $B_{\mathrm{t}}$ is due to the latent heat flux dominating the thermal part of the buoyancy fluxes. Hence, $B_{\mathrm{s}}$ and $B_{\mathrm{t}}$ are both correlated to the evaporation.

There is a significant correlation between $\alpha \Delta T$ and $\Delta B t$, but none between $\beta \Delta S$ and $\Delta B_{\mathrm{s}}$, because $B_{\mathrm{t}} \gg B_{\mathrm{s}}$, as shown on Fig. 8. It confirms that the salinity variations only follow the temperature ones (density compensation), as also emphasised by the good correlation between $\beta \Delta S$ and $\Delta B_{\mathrm{t}}$.

The poor correlation between $\beta \Delta S$ and $\Delta B_{\mathrm{S}}$ explains the poor correlation between the ratios $\frac{\alpha \Delta T}{\beta \Delta S}$ and $\frac{\Delta B_{\mathrm{t}}}{\Delta B_{\mathrm{S}}}(0.018)$, and leads us to conclude that the ratio $\frac{\Delta T}{\Delta S}$ must be set by the pre-convection heat and salt contents. Hence, the variability of preconditioning must be responsible for the variability of the deep water $\mathrm{T} / \mathrm{S}$, unless cascading is important. The lateral buoyancy fluxes occurring during convection are not expected to change this conclusion as the water they import into the convective patch is similar to the preconditioned water.

\section{Conclusions}

The variability of hydrographic preconditioning is characterised at the Medoc and Dyfamed sites. The stratification in the intermediate layer is found to reach a maximum in December, likely due to the Tyrrhenian Current crossing the Corsica Strait only in winter. The interannual variability of this maximum is shown to be closely linked to the density in the intermediate layer. In a 1-D framework, we find that hydrographic preconditioning is as important as the winter buoyancy fluxes in setting the convective mixed layer depth. Particularly, it was found that even a normal winter would have lead to deep convection in 2004-2005 due to preconditioning. The severe winter thus led to the formation of a massive amount of new deep water (Schroeder et al., 2008).

Interannual variability at the Dyfamed site indicates that most of the variability in heat and salt contents is due to the top and intermediate layers. This large year to year variability may hide trends that are not apparent yet due to the length of the data set (10 years). However, temperature and salinity in the deep layer follow an increasing trend similar to that observed by Lopez-Jurado et al. (2005), thought to be linked to basin scale changes. We have shown here that they coincide with colder, saltier and denser top and intermediate layers at the Dyfamed site.

Correlation tests between the winter surface fluxes and the properties of the deep water formed by convection show that the temperature and salinity are set by hydrographic preconditioning. As the winter buoyancy fluxes are largely dominated by the heat fluxes, the salinity of the deep water formed is mostly set by the salt content of the water column before convection, while its temperature results from a combination of the initial heat content and the surface heat fluxes.

These results support the description of convection as a process that transfers properties from the top and intermediate layers into the deep layer, with a rate of transfer for which the final convective mixed layer depth is a proxy that depends both on the surface heat fluxes and on the preconditioning.

Acknowledgements. The data used in this study were made available by the Laboratoire d'Océanographie de Villefranche (Dyfamed), the Medar network, NCEP and Jean-Pierre Béthoux. Funding was provided by the NOC, Southampton, the NERC Strategic Research Division, the National Marine Facilities Division, NERC grant Oceans 2025 and NERC grant NE/B505911/1. We would like to thank Gwyn Griffiths and Pierre Testor for useful suggestions and discussions.

Edited by: K. J. Heywood

\section{References}

Alverson, K.: Mechanisms for lateral exchange with oceanic convection sites, J. Phys. Oceanogr., 27, 1436-1446, 1997.

Artale, V., Iudicone, D., Santoleri, R., Rupolo, V., Marullo, S., and D’Ortenzio, F.: Role of surface fluxes in ocean general circulation models using satellite sea surface temperature: Validation of and sensitivity to the forcing frequency of the Mediterranean thermohaline circulation, J. Geophys. Res.-Oceans, 107, 3120, doi:10.1029/2000JC000452, 2002. 
Astraldi, M. and Gasparini, G.: The Seasonal Characteristics of the Circulation in the North Mediterranean Basin and their Relationship with the Atmospheric-Climatic Conditions, J. Geophys. Res.-Oceans, 97, 9531-9540, 1992.

Astraldi, M., Gasparini, G., Manzella, G., and Hopkins, T.: Temporal Variability of Currents in the Eastern Ligurian Sea, J. Geophys. Res.-Oceans, 95, 1515-1522, 1990.

Béthoux, J. P., Gentili, B., Raunet, J., and Tailliez, D.: Warming trend in the Western Mediterranean deep water, Nature, 347, 660-662, 1990.

Béthoux, J. P., Gentili, B., and Tailliez, D.: Warming and freshwater budget change in the Mediterranean since the 1940s, their possible relation to the greenhouse effect, Geophys. Res. Lett., 25, 1023-1026, 1998.

Béthoux, J. P., De Madron, X., Nyffeler, F., and Tailliez, D.: Deep water in the Western Mediterranean: peculiar 1999 and 2000 characteristics, shelf formation hypothesis, variability since 1970 and geochemical inferences, J. Mar. Syst., 33, 117-131, doi: PIIS0924-7963(02)00055-6, 2002.

Bryden, H. L. and Stommel, H. M.: Limiting processes that determine basic features of the circulation in the Mediterranean Sea, Oceanologica Acta, 7, 289-296, 1984.

Canals, M., Puig, P., de Madron, X. D., Heussner, S., Palanques, A., and Fabres, J.: Flushing submarine canyons, Nature, 444, 354-357, 2006.

Font, J., Puig, P., Salat, J., Palanques, A., and Emelianov, M.: Sequence of hydrographic changes in NW Mediterranean deep water due to the exceptional winter of 2005, Scientia Marina, 71, 339-346, 2007.

Gascard, J. C.: Mediterranean deep water formation, baroclinic instability and oceanic eddies, Oceanologica Acta, 1, 315-330, 1978.

Gasparini, G., Schroeder, K., and Sparnocchia, S.: Straits and Channels as key regions of an integrated marine observatory of the Mediterranean: our experience on their long-term monitoring, in: Towards an Integrated System of Mediterranean Marine Observatories., vol. 34 of CIESM Workshop Monographs, pp. 75-79, CIESM, 2008.

Grignon, L.: Causes of the interannual variability of deep convection, $\mathrm{PhD}$ thesis, University of Southampton, 2009.

Herrmann, M., Somot, S., Sevault, F., and Estournel, C.: Modeling the deep convection in the northwestern Mediterranean Sea using an eddy-permitting and an eddy-resolving model: Case study of winter 1986-1987, J. Geophys. Res., 113, C04011, doi:10.1029/ 2006JC003991, 2008.

Hogg, N. G.: The preconditioning phase of MEDOC 1969 - II. Topographic effects, Deep-Sea Res., 20, 449-459, 1973.

Hogg, N. G. and Stommel, H. M.: Hetonic explosions: The breakup and spread of warm pools as explained by baroclinic point vortices, J. Atmos. Sci., 42, 1465-1476, 1985.

Kinder, T. and Bryden, H.: The Physical Oceanography of Sea Straits, chap. The aspiration of deep waters through Straits, pp. 295-319, The Physical Oceanography of Sea Straits, 1990.

Krahmann, G. and Schott, F.: Longterm increases in Western Mediterranean salinities and temperatures: anthropogenic and climatic sources, Geophys. Res. Lett., 25, 4209-4212, 1998.

Legg, S. and Marshall, J.: A heton model of the spreading phase of open-ocean deep convection, J. Phys. Oceanogr., 23, 1040-1056, 1993.
Legg, S., McWilliams, J., and Gao, J. B.: Localization of deep ocean convection by a mesoscale eddy, J. Phys. Oceanogr., 28, 944-970, 1998.

Lopez-Jurado, J. L., Gonzalez-Pola, C., and Velez-Belchi, P.: Observation of an abrupt disruption of the long-term warming trend at the Balearic Sea, Western Mediterranean Sea, in summer 2005, Geophys. Res. Lett., 32, L24606, doi:10.1029/2005GL024430, 2005.

Madec, G., Lott, F., Delecluse, P., and Crépon, M.: Large-scale preconditioning of deep-water formation in the Northwestern Mediterranean Sea, J. Phys. Oceanogr., 26, 1393-1408, 1996.

Marshall, J. and Schott, F.: Open-ocean convection: Observations, theory, and models, Rev. Geophys., 37, 1-64, 1999.

Marshall, J., Dobson, F., Moore, K., Rhines, P., Visbeck, M., d'Asaro, E., Bumke, K., Chang, S., Davis, R., Fischer, K., Garwood, R., Guest, P., Harcourt, R., Herbaut, C., Holt, T., Lazier, J., Legg, S., McWilliams, J., Pickart, R., Prater, M., Renfrew, I., Schott, F., Send, U., and Smethie, W.: The Labrador Sea deep convection experiment, B. Am. Meteorol. Soc., 79, 2033-2058, 1998.

Marty, J. C. and Chiavérini, J.: Hydrological changes in the Ligurian Sea (NW Mediterranean, DYFAMED site) during 19952007 and biogeochemical consequences, Biogeosciences Discuss., 7, 1377-1406, doi:10.5194/bgd-7-1377-2010, 2010.

Marty, J., Chiaverini, J., Pizay, M., and Avril, B.: Seasonal and interrannual dynamics of nutrients and phytoplankton pigments in the wester Mediterranean Sea at the DYFAMED time-series station (1991-1999), Deep-Sea Res. II, 49, 1965-1985, 2002.

MEDOC-Group: Observation of formation of deep water in the Mediterranean Sea, 1969, Nature, 227, 1037-1040, 1970.

Merckelbach, L., Smeed, D., and Griffiths, G.: Vertical Water Velocities from Underwater Gliders, J. Atmos. Oceanic Technol., 27, 547-563, doi:10.1175/2009JTECHO710.1, 2010.

Mertens, C. and Schott, F.: Interannual variability of deepwater formation in the Northwestern Mediterranean, J. Phys. Oceanogr., 28, 1410-1424, 1998.

Millot, C.: Interannual salinification of the Mediterranean inflow, Geophys. Res. Lett., 34, L21609, doi:10.1029/2007GL031179, 2007.

Painter, S. and Tsimplis, M.: Temperature and salinity trends in the upper waters of the Mediterranean Sea as determined from the MEDATLAS dataset, Cont. Shelf Res., 23, 1507-1522, doi: 10.1016/j.csr.2003.08.008, 2003.

Rohling, E. and Bryden, H.: Man-induced salinity and temperature increases in Western Mediterranean Deep-Water, J. Geophys. Res.-Oceans, 97, 11191-11198, 1992.

Schott, F. and Leaman, K. D.: Observations with moored Acoustic Doppler Current Profilers in the convection regime in the Golfe Du Lion, J. Phys. Oceanogr., 21, 558-574, 1991.

Schott, F, F., Visbeck, M, M., and Fischer, J.: Observations of vertical currents and convection in the central Greenland Sea during the winter of 1988-1989, J. Geophys. Res.-Oceans, 98, 1440114421, 1993.

Schroeder, K., Gasparini, G., Tangherlini, M., and Astraldi, M.: Deep and intermediate water in the Western Mediterranean under the influence of the Eastern Mediterranean Transient, Geophys Res. Lett., 33, L21607, doi:10.1029/2006GL027121, 2006.

Schroeder, K., Ribotti, A., Borghini, M., Sorgente, R., Perilli, A., and Gasparini, G.: An extensive Western Mediterranean Deep 
Water Renewal between 2004 and 2006, Geophys. Res. Lett., 35, L18605, doi:10.1029/2008GL03514, 2008.

Schroeder, K., Josey, S., Herrmann, M., Grignon, L., Gasparini, G., and Bryden, H.: Abrupt warming and salting of the Western Mediterranean Deep Waterafter 2005: atmospheric forcing and lateral advection., J. Geophys. Res., doi:10.1029/2009JC005850, in press, 2010.

Send, U. and Marshall, J.: Integral effects of deep convection, J. Phys. Oceanogr., 25, 855-872, 1995.

Smith, R. O., Bryden, H. L., and Stansfield, K.: Observations of new western Mediterranean deep water formation using Argo floats 2004-2006, Ocean Sci., 4, 133-149, doi:10.5194/os-4133-2008, 2008.
Stommel, H., Bryden, H., and Mangelsdorf, P.: Does some of Mediterranean outflow come from great depth?, Pure Appl. Geophys., 105, 879-889, 1973.

Testor, P. and Gascard, J. C.: Post-convection spreading phase in the Northwestern Mediterranean Sea, Deep-Sea Res. Part IOceanographic Research Papers, 53, 869-893, doi:10.1016/j.dsr. 2006.02.004, 2006.

Vignudelli, S., Gasparini, G., Astraldi, M., and Schiano, M.: A possible influence of the North Atlantic Oscillation on the circulation of the Western Mediterranean Sea, Geophys. Res. Lett., 26, 623-626, 1999.

Voorhis, A. D. and Webb, D. C.: Vertical currents in a winter sinking region, Transactions-American Geophysical Union, 51, 315, 1970 . 